\title{
DEVELOPING THE CRITICAL THINKING SKILLS OF STUDENTS IN CIVIL AND BUILDING ENGINEERING AT LOUGHBOROUGH UNIVERSITY
}

\author{
Lynda Gibbins, Glynis Perkin, Graham Sander \\ Loughborough University (UNITED KINGDOM)
}

\begin{abstract}
This research investigated the critical thinking skills of undergraduate students in Civil and Building Engineering (CBE) at Loughborough University. In particular it focused on individual students' perceptions of what critical thinking entailed, the views of staff regarding the students' ability in this area, especially relating to final year research projects, and modules where critical thinking skills were addressed and assessed. The attitude to critical thinking by students from different cultures and countries was also examined. There are seven different programmes within CBE and differences in student ability and module content were compared and contrasted between programmes, with particular focus on modules studied during the first two years at university. The focus on modules prior to the final year of study was a result of Programme Directors and Project Supervisors reporting that students are not adequately demonstrating critical thinking skills when undertaking research-based tasks in their final year of study.

A questionnaire, which was designed to gain an insight into students' understanding of critical thinking, was completed by 39 students from five different programmes of study. In addition to preliminary discussions with all Programme Directors in the School, ten academic members of staff were interviewed to determine their views on the level of critical thinking demonstrated by the students and their own level of focus on this skill in their teaching. The findings from the questionnaires and interviews were then related to the modules of study for these programmes and a map detailing gaps in exposing students to this skill were produced.

The findings show that from the student perspective the majority of those surveyed do understand what critical thinking involves and believe this to be important to their future working lives. However, from the staff perspective it appears that, in the main, students do not demonstrate aspects of critical thinking unless explicitly asked to do so and students who do demonstrate critical thinking, for example, when undertaking research projects do not do it at the level that is expected. If students are to view critical thinking as an important part of their development then it is essential that these skills are assessed in more modules. This will ensure that students enter the workplace with the ability to analyse situations, challenge the views of others and make informed decisions.
\end{abstract}

Keywords: Critical thinking, employability, lifelong learning.

\section{BACKGROUND TO THE RESEARCH}

The School of Civil and Building Engineering (CBE) at Loughborough University is keen to improve students' critical thinking (CT) skills, and their ability to apply these skills, especially when undertaking research-based projects. The research was undertaken by The Centre for Engineering and Design Education (CEDE) at Loughborough University to identify any gaps or variations in coverage of CT skills throughout the CBE undergraduate programmes, and to propose strategies to help students to develop these skills throughout and beyond their undergraduate journey.

The perception expressed by Programme Directors in CBE was that many students do not demonstrate CT when approaching research-based tasks and final year projects. They identified that the majority of $\mathrm{CBE}$ undergraduate students take a Communication module which explicitly teaches aspects of CT, but there is a view that after this module, there is little explicit teaching of these skills during most students' subsequent studies. There was also a belief that the modularisation of education, which starts in school and continues into higher education (HE), diminishes the interconnectedness of areas of study and results in students not transferring knowledge and skills from module to module and into their subsequent working life [1], [2]. 


\section{INTRODUCTION}

An ability to think critically is of paramount importance to scientists and engineers, whose work typically involves problem-analysis, evaluation of possible courses of action and decision-making. The Accreditation Board for Engineering and Technology (ABET) criteria [3] for accrediting engineering programmes contains several outcomes for which CT skills are implicit. Furthermore, educators have long debated how best to teach or encourage CT skills in HE students, see, for example, [4], [5], [6].

Our aim was to gain an insight into the extent of teaching and assessment of CT skills and students' understanding and application of these skills as they progress through their studies. As there are a large number of modules, compulsory and optional, available to CBE students across the seven degree programmes, we focused on compulsory modules. For each programme of study we then reviewed the module specifications for the compulsory modules in Part A (year 1) and Part B (year 2) plus year 3 for the 4-year MEng programme, to determine which ones contained elements of CT. We focused on non-final year modules as the Programme Directors expressed the view that when embarking on their final year, students are not adequately demonstrating CT in their approach to research-based tasks. Ideally, the compulsory modules taken before the final year should embed these skills in students and equip them for their subsequent research-based work.

\subsection{What is critical thinking?}

Many scholars and academics have proposed definitions of CT, see, for example, [7], [8]. In 1909, John Dewey [9], an American philosopher, psychologist and educator called it "reflective thinking" and emphasised that it is an active process rather than passively learning from others.

Edward Glaser [10] proposed that the ability to think critically requires three components:

1 An attitude of being disposed to consider in a thoughtful way the problems and subjects that come within the range of one's experiences

2 Knowledge of the methods of logical inquiry and reasoning

3 Some skill in applying those methods.

Oxford Dictionaries [11] define critical thinking as "The objective analysis and evaluation of an issue in order to form a judgement".

In 1956 what has become known as 'Bloom's Taxonomy' [12] was created under the leadership of Dr Benjamin Bloom, an educational psychologist. This taxonomy categorises three domains of learning; cognitive (knowledge skills), affective (emotional areas) and psychomotor (manual or physical skills). The cognitive domain, referring to the development of intellectual skills, contains six hierarchical categories ranked from lowest to highest order of thinking skills which are of particular interest in relation to CT skills:

- Knowledge

- Comprehension

- Application

- Analysis

- Synthesis

- Evaluation

Taking into account the definitions cited above and our own understanding of critical thinking, for the purposes of this research we have introduced a list of CT components as the ability to:

- Analyse situations, problems, claims etc.

- Identify assumptions and bias

- Judge credibility of evidence or claims

- Evaluate arguments

- Produce well-founded arguments

- Draw well-founded conclusions. 


\subsection{Critical thinking in higher education}

In addition to the publications already referred to, in 2011 the Higher Education Research and Development Journal [13] published a special issue dedicated to CT in HE. This issue contains an introduction and ten papers, written by staff from HE institutions (HEIs) in Australia, New Zealand, the UK and the USA. In his introduction, Davies reports on the serious lack of CT and reasoning skills demonstrated by undergraduate students. The papers, in the main, are from the Australasian region; hence, it is clear that this is not just a problem occurring in UK institutions. These papers explore different approaches to the teaching of CT.

The international mix of students at HEls means that UK or Western traditions of what CT entails cannot be assumed to be unanimously understood by all students. Differing cultures have different perspectives, values and traditions [14]. Therefore the principles of CT must be clearly and explicitly stated so that students can develop a common understanding of what is expected of them. Furthermore, Floyd [15] points out that although students from Asian cultures are perceived to be less skilled in CT there is an associated challenge in thinking critically in a second language.

\subsection{Critical thinking in the workplace}

The workplace is a fast-changing and competitive world, and for companies and organisations to succeed, they need to be able to adapt quickly without undue attachment to previous ways of operating. The ability to analyse a new and complex situation, to challenge accepted wisdom and to make rational, unemotional decisions based on identification and analysis of relevant information is paramount to success. Employees who have the skills to respond to these challenges will do well. Indeed, the business magazine Forbes [16] reports that CT is the top job skill required by employers.

The UK Standard for Professional Engineering Competence (UK-SPEC) [17] provides qualification descriptors for accredited degree programmes. These describe the attributes that a holder of an engineering bachelor's degree with honours from an accredited programme should possess. Amongst these attributes, a graduate should be able to: "...critically evaluate arguments, assumptions, abstract concepts and data (that may be incomplete), to make judgements, and to frame appropriate questions to achieve a solution - or identify a range of solutions - to a problem". The International Engineering Alliance (IEA) [18] has also published a set of Graduate Attributes and Professional Competencies. It is apparent that to meet either UK-SPEC or IEA competency profiles, an engineer must employ the component skills of $\mathrm{CT}$, analysing problems, evaluating options, and making well-founded judgements.

Taking a wider perspective and looking beyond the confines of engineering, many situations that arise in any workplace will benefit from the application of CT processes. Employing these skills means that problems will be analysed in a more objective way, underlying assumptions will be challenged and options for solutions will be carefully evaluated, leading to better decision-making. These are skills that anyone, graduate or not, engineer or not, should be encouraged to develop.

\section{OVERVIEW OF OUR APPROACH}

Initially, pertinent research and areas of good practice across the HE sector were identified from published literature. Following this, there were three different strands to our research and analysis; firstly a study of modules with content and assessment relating to CT which was informed by the Programme Directors, secondly the findings from questionnaires distributed to students and finally interviews with members of staff which focused on their experience of supervising final year projects with an emphasis on students' application of critical thinking.

\subsection{Keywords used to analyse module specifications}

The following key words and phrases were identified as being indicative of critical thinking and were developed from our working definition described in section 2.1:

$\begin{array}{ll}\text { Justify } & \text { Analyse } \\ \text { Compare and contrast } & \text { Evaluate / critically evaluate } \\ \text { Identify } & \text { Select appropriate (method etc.) } \\ \text { Informed decision / judgement } & \text { Categorise } \\ \text { Conclusion based on evidence } & \text { Defend / justify your answer }\end{array}$


Reflect(ive)

Reasoned argument
Judge (evidence / claims etc.)

Logical reasoning.

\subsection{Module analysis}

When analysing the selected non-finalist compulsory module specifications, assessment tasks and assessment criteria across all CBE undergraduate programmes, we used the aforementioned set of keywords to identify those modules teaching or assessing CT skills. From this, a mapping of the student pathway was undertaken to identify any areas of perceived high or low coverage.

\subsection{Student questionnaires and staff interviews}

Student views and understanding of key terms were explored by means of a small survey. Members of CBE staff were interviewed to gain their perception of students' understanding and application of CT skills with particular focus on the level of skill demonstrated by them in final year research projects.

\section{MAPPING THE CURRENT STUDENT JOURNEY}

For each module where we found some elements of CT explicitly stated in the specification, we further analysed the assessment tasks and assessment criteria to determine whether the skills mentioned in the Intended Learning Outcomes (ILOs) were in fact assessed by coursework or examination. In this way, for each programme of study, we identified those modules that contain elements of CT skills which are then assessed. By comparing degree programmes, there appears to be two programmes where there is a lesser coverage of critical thinking in a student's journey.

From our analysis of the available information, it appears that in only 21 out of 93 non-final year compulsory modules across CBE is CT both explicitly taught, and assessed. However, this should be taken as an indicative result since at the time of analysis not all module information was available.

\subsection{The ideal student journey}

Evidence suggests that students develop higher order thinking skills over a prolonged time frame, by repeated exposure to the type of thinking required [19]. Critical thinking approaches must be embedded into the programme of study and nurtured throughout a student's learning journey. These skills cannot be taught and developed by a one-off occurrence in a single module. Ideally, students should be exposed to and encouraged to practise CT at every stage of their studies, since this promotes deep rather than surface learning.

\subsection{Gap analysis}

Our analysis shows that most CBE Part A students study the Communication module, which provides an introduction to CT skills. For most CBE programmes, it seems that there are at least two compulsory modules in Part A and Part B that explicitly refer to and assess CT. However, for students on the BEng and MEng programmes, there seems to be less coverage in their modules. The only module found explicitly covering CT on these programmes was 'Communication' in Part A. Unless these skills are reinforced by repeated exposure and practice, there is a danger that when students embark on their final year projects they will not apply a critical approach without it being explicitly requested. It appears that there are opportunities to reinforce CT and analysis in later modules, to encourage students to become more skilled critical thinkers.

\section{STUDENT VIEWS}

A questionnaire was developed to gain an insight into current CBE students' understanding of CT and its place in their programmes. Students were approached as they handed in coursework on a single day and asked if they would participate in this study by completing the questionnaire. Almost all students approached agreed to participate, and a total of 39 completed questionnaires were obtained. Although this questionnaire did not obtain responses from all the undergraduate programmes in the School, and was a small scale survey, some interesting pointers to students' understanding of critical thinking in their studies have emerged. 


\subsection{Students' understanding of critical thinking}

To investigate students' understanding of the term 'critical thinking', they were asked 'What words do you associate with critical thinking?" Most respondents offered one or more words or phrases which were analysed and grouped into broad categories. The most frequent responses that showed evidence of understanding the meaning of critical thinking were: "Analysis, problem solving, evaluate, interpret" and "Thinking critically / deeply".

It is encouraging that of the 39 students, only two failed to answer this question and one response was illegible. In addition, although there were 14 terms deemed to be irrelevant to CT, there were only three students who offered no relevant terms amongst their suggestions. The most frequently proposed terms correspond closely to aspects of CT in our working definition.

\subsection{Coverage of critical thinking in modules}

Students were asked "In which modules have you encountered critical thinking during your studies?" Of the 39 respondents, 12 stated that all or most of their modules contained references to CT. By contrast, two students stated that none of their modules contained it, one left the question unanswered, one stated that it was covered mainly in postgraduate studies and one stated "N/A". Four students named three or four specific modules, and a further 18 students named one or two modules.

\subsection{Reasons for developing critical thinking skills}

In response to the question "Is it important to acquire these skills?", 38 of the students answered "Yes" and only one answered "No", qualified by the statement that 16-18 year old study has already developed these skills. The follow-up question asking why it is (or is not) important elicited a diverse set of responses which were grouped into broad themes. The most commonly cited responses were "Important for work or study" and "Life skills / real world importance". Some students provided more than one response, and 12 students (31\%) did not give a response, which is of some concern.

\subsection{How frequently do your lecturers mention these skills?}

Students were asked how often CT skills were mentioned by their lecturers; the results are shown in Fig. 1. Although this was a small survey, the responses from students on the BEng / MEng programmes are in line with our "gap analysis" in 4.3 , where we found that there seems to be less explicit teaching and assessing of critical thinking in these programmes.

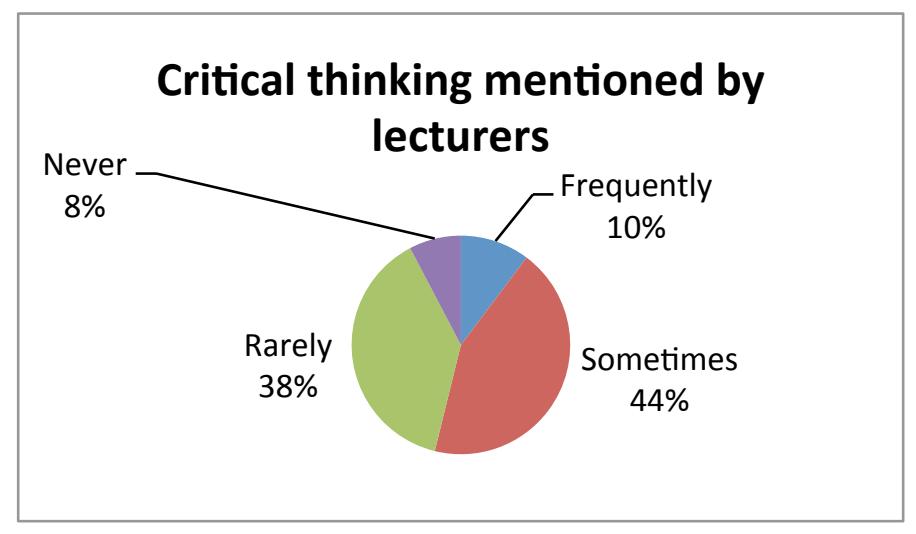

Fig. 1: Students' perceptions of how frequently lecturers mention critical thinking skills

\subsection{Are critical thinking skills assessed in your programme?}

Students were also asked whether CT skills are assessed during their studies and if so the frequently of this, see Fig 2. 


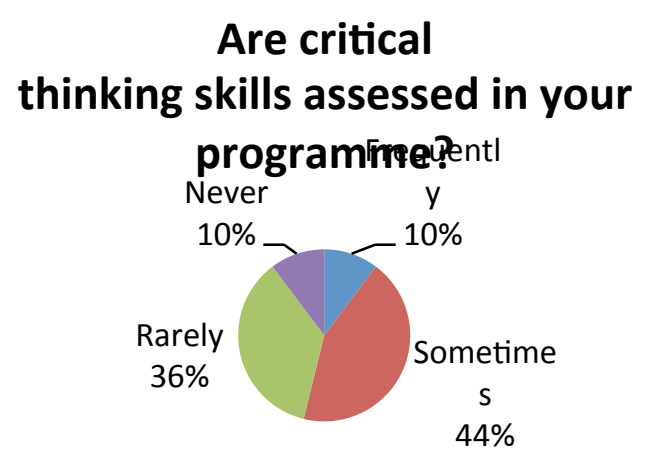

Fig. 2: Students' perceptions of how frequently critical thinking skills are assessed

A similar picture emerged, with the largest response being "Sometimes".

\subsection{The role of tutorials in promoting self-reflection}

Tutorials can provide opportunity for students to reflect on their work and with the help of the tutor develop a more critical approach to their work. In several module specifications this use of tutorial time is explicitly mentioned. Of our group of 39 students, 26 agreed that tutorials do provide this opportunity; one stated that they sometimes do, whilst ten disagreed. Two students did not respond to this question. By way of explanation, several students mentioned that there was insufficient time in tutorials to engage in self-reflection, or that tutorials are largely used to work through problem sheets. Clearly the module content will have an impact on the use of tutorial time; technical material will require more time to be spent on worked examples.

Of the students who felt that tutorials support self-reflection, one stated: "They allow students to see which areas they are slipping up in and which areas they are performing well in, and this can also aid students in their revision with which areas to concentrate on most". Another student agreed that the tutor: "Helps you look over your work". Two students felt that tutorials do not allow self-reflection, one stated: "Should be conducted differently. Most tutorials just make you sit there and work problems. I can do that at home. Teach me".

The responses again revealed different responses related to programme of study. Six out of the eight BEng/MEng students said that their tutorials do not provide opportunities for self-reflection, whilst the majority of students on the other programmes believed that they do provide opportunity.

\subsection{What more could be done to develop critical thinking}

Students were asked to put forward suggestions for what more their School or University could do to help them develop CT skills. Seven stated "nothing", "N/A" or "Don't know", and six did not respond. The suggestions put forward by the other respondents are shown in Fig. 3.

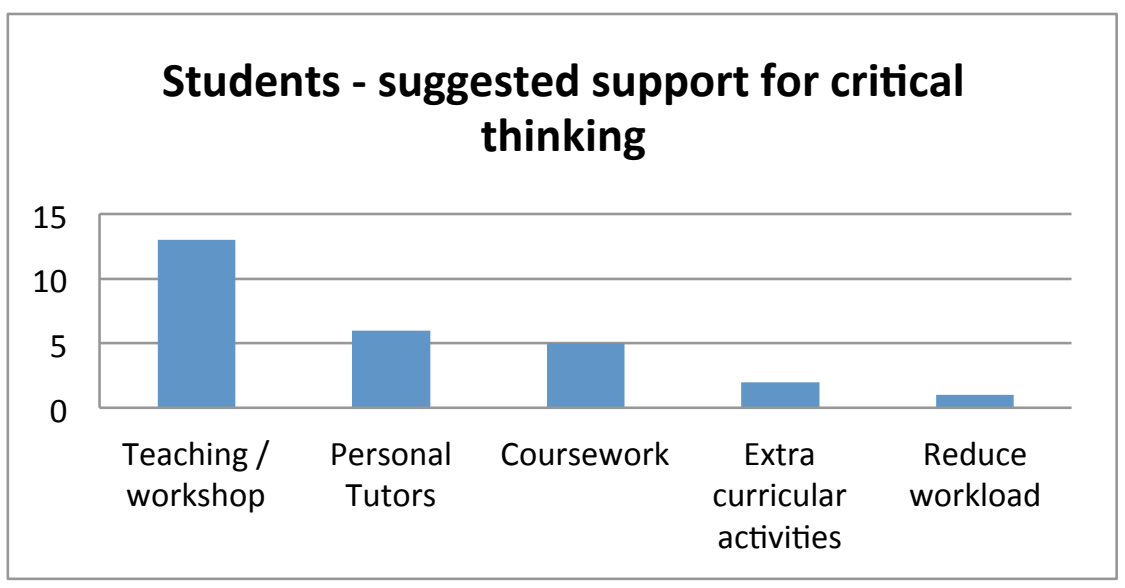

Fig. 3: Students - suggested support for critical thinking 
It appears that students want more explicit teaching of critical thinking in lectures or tutorials, backed up by coursework. One comment illustrates this: "Get all lecturers to highlight the importance of it...".

\subsection{The student perspective - a summary}

In summary, most of the students in our survey have a reasonable grasp of what CT entails, and almost unanimously believe that it is important to develop these skills. The majority could recall at least one module in which CT was encountered, though the specific modules they mentioned were not always those that appeared from the module specifications to have the highest level of CT content or evidence of assessment. When questioned about how frequently these skills are mentioned and assessed, slightly under half the respondents believed this happened "Never" or "Rarely". Only 14 of our 39 respondents were aware of any resources or sources of support for CT, although the majority felt that tutorials do (or could) provide an opportunity for self-reflection, aided by the tutor.

There appear to be differences in the responses to some of our questions based on the degree programmes, with the BEng / MEng students reporting less teaching and less assessment of CT and also predominantly reporting that their tutorials do not provide opportunities for self-reflection. However, our small survey can only provide indicators to potential issues for further investigation.

\section{STAFF INTERVIEWS}

A total of ten academic staff from across all undergraduate programmes in the School were interviewed to discover their views on the CT skills of their students and to explore their practice when teaching.

\subsection{Students display a range of abilities}

Most of the staff interviewed described a wide range of CT skills among final year students, from extremely proficient to very poor, with many expressing disappointment in the abilities of the majority. Some students seem to have mastered the principles of critical analysis, while others require much more guidance on how to approach research-based projects. There was recognition that cultural traits may account for the difficulties some students experience. UK and EU-based students are comfortable with developing and defending their own opinions, whereas in some Asian education systems and cultures it is considered disrespectful to question perceived 'experts'. Some staff believe that school background may also account for some differences, with private schools seen as requiring students to do more critiquing than UK state schools.

Students undertaking a programme where they have been selected at interview by the School and a sponsoring employer on the basis of their management potential, in addition to their academic record, were felt, in general, to be very good critical thinkers. MEng students were reported to be of higher than average ability and to be generally more committed. The placement year is viewed as being transformative, producing real improvement in students' abilities to think critically when solving problems. However, as members of staff have reported that students have less than acceptable CT skills even in their final year, it is apparent that this is an area that needs to be repeatedly reinforced. This in accord with Wass et al., [20] who write that critical thinking is "a lifelong learning skill".

\subsection{Students work strategically}

Our current modularised HE system with quite detailed prescriptive module specifications and ILOs is felt by several lecturers to allow students to "chase the marks" and work strategically. Students will put most effort into areas where they see that marks are awarded. Some appear to "tick off" chunks of work and show no evidence of applying these skills in later modules.

\subsection{Critical writing}

The standard of literature reviews was generally reported to be poor, with many students producing entirely descriptive writing. Despite the majority of undergraduates in CBE having taken the Communication module in Part $A$, by the time they embark on a research project in their final year many showed no recollection of the principles of critically evaluating the work of others, and little ability to assess relevance or context of previous reported work. There is also a poor understanding of the difference in terms of academic legitimacy between different types of publications. 


\subsection{Supporting students}

Generally, students arrive at university as non-critical thinkers. The prevailing view from the staff interviewed was that to support students in developing CT skills every effort should be made to embed these skills throughout a student's undergraduate programme. A consistent approach should be employed with explicit expectations set at the outset about their development as critical thinkers. Most interviewees feel that rather than try to teach these skills explicitly as a separate entity, the required approach should be embedded in the assessment tasks and marking schemes at all levels. Several staff explained how they take every opportunity to emphasise a critical approach and the need to challenge or defend a particular position, rather than just stating the method used.

A view was expressed that there is a common misunderstanding among students about the word "critical", in that it implies criticism and students are wary of criticising others' reported work. For this reason, one lecturer avoids the term critical thinking and instead emphasises a questioning approach, by encouraging students to ask "what, who, where, why" while they are reading.

\subsection{Assessment of critical thinking}

Staff acknowledged that it is easier to assess knowledge than CT skills, and several stated that they want to do more to assess CT skills. If the development of CT skills is seen as important, then undergraduate programmes should provide opportunities to learn and practise these approaches, and assessment tasks and criteria should reflect the importance attached to these skills.

\subsection{Overview of staff views}

As detailed above there is a range of suggestions regarding how to improve students' CT skills and a mixed perception regarding the ability of students to think critically. However, members of staff are in agreement regarding the importance of students being able to critique and appraise material, and the need for development of these skills to be embedded throughout degree programmes.

\section{OVERALL FINDINGS}

Our aim was to gain an insight into the extent of teaching and assessment of CT skills and students' understanding and application of these skills as they progress through their studies. From the student perspective it is apparent that the majority of those surveyed do understand what CT involves and also believe this to be important to their future working lives. However, from the staff perspective it appears that, in the main, students do not demonstrate aspects of CT unless explicitly asked to do so and even when using CT when undertaking research projects it generally is not at a high level. If students are to view CT as an essential part of their development then it must be assessed in more modules. The analysis of module specifications indicated that students on the BEng and MEng programmes are exposed to less formal teaching and assessment of critical thinking. This appears to be borne out by the responses made by students when asked how often their lecturers mentioned or assessed critical thinking. However, the situation is complex, as many staff ranked MEng students highly in terms of their CT ability.

\section{STRATEGIES TO INCREASE CRITICAL THINKING SKILLS}

Two strategies could be adopted to promote the development of CT skills in students, in addition to the provision of further resources for self-directed study. One approach is related to the teaching of critical thinking and the other is related to assessment practice.

\subsection{How can critical thinking be taught?}

It used to be the case that students were expected to develop CT skills by way of studying their subject, in other words to assimilate them implicitly in the course of their studies. However, the evidence seems to be that students do not improve their critical thinking skills this way. Increasingly, educators are looking to teach these skills explicitly [21].

To develop CT skills, students must be encouraged to go beyond simple regurgitation of remembered facts, therefore opportunities for deeper analysis and synthesis of multiple facts in complex real-world scenarios should be presented to them. If this approach is embedded in all modules throughout 
students' learning journeys, they should become increasingly skilled practitioners, developing greater depth of thought as they progress through their course.

There are many other examples of approaches to teaching CT in the literature, for example, Felder et al. [22] state that to teach students to think creatively and critically, teachers should: "...show them examples of the kind of thinking you have in mind; ask them in class and in assignments to complete tasks that require that kind of thinking; give them feedback; and repeat". They also provide examples of tasks that can be incorporated into any course to encourage and assess creative and critical thinking. Gunnink et al. [23] provide several examples of writing assignments for engineering students which are designed to foster critical thinking.

Students can be taught to appraise published research papers critically by adopting a structured approach to reviewing them. Playle [24] provides one such framework for critical appraisal of research reports. This framework is used in the Communication module taken by most CBE undergraduates.

\subsection{How can critical thinking skills be assessed?}

Clear assessment criteria enable students to recognise that $\mathrm{CT}$ is required, and to see the importance of critically evaluating their own work in order to produce valid arguments and opinions. In order to demonstrate a clear progression in CT ability, it is necessary to assess these skills and develop a set of benchmarks or rubrics against which to measure a student's progress. There are several examples of rubrics developed by further and higher education practitioners, particularly in the US, see for example [25], [26].

\section{RECOMMENDATIONS AND FUTURE WORK}

The following is a list of possible strategies that might be employed to help to develop students' CT skills... The strategies, in the main, are not arduous but require buy-in, to a lesser or greater degree, by all members of staff responsible for module delivery and tutorial input.

- Develop an approach to CT to cover all programmes and all years.

- Explain to students what is expected of them as they become independent learners.

- Incorporate more essay-based assessed tasks into assessments

- More explicit teaching throughout undergraduate programmes and staff to highlight when CT skills are encountered and the importance of these skills.

- Emphasise the need to embed such skills and carry them forward into later work.

- Modify assessment tasks award marks for CT skills e.g. compare / contrast; justify.

- Develop or adapt a set of benchmarks (rubrics) to describe and measure the progression of CT skills throughout a student's journey.

- Show students examples of good (and bad) coursework, reports etc.

- Where possible allow time in tutorials for reflective thinking.

- Develop or purchase additional resources to support students.

\section{REFERENCES}

[1] Goodhew, P. (2002). Modularisation and Sliced Bread. Available at: http://www.materials.ac.uk/discuss/modularisation.asp [Accessed 16 Dec 2015]

[2] Heinrich, M. and Stringer, N. (2012). The effects on schools and pupils of modularising GCSEs. Manchester: AQA Centre for Education Research and Policy. Available at: https://cerp.aqa.org.uk/research-library/effects-schools-and-pupils-modularising-gcses [Accessed 16 Dec 2015]

[3] ABET. (2015). Criteria for Accrediting Engineering Programmes, 2015-2016. Available at: http://www.abet.org/eac-criteria-2015-2016/ [Accessed 16 Dec 2015]

[4] Davies, M. \& Barnett, R. (Eds) (2015). The Palgrave Handbook of Critical Thinking in Higher Education. Palgrave Macmillan. 
[5] Fogler, H.S. \& LeBlanc, S.E. (2008). Strategies for Creative Problem Solving, second edition. Pearson Education, Inc. New Jersey, USA.

[6] Leopold, T. \& Vickerman, P. (2010). Learning and Teaching Guide on Critical Thinking. Higher Education Academy, York, UK. Available at:

https://www.heacademy.ac.uk/sites/default/files/ssg_leopold_critical_thinking.pdf [Accessed 16 Dec 2015]

[7] The Critical Thinking Community, Defining Critical Thinking. (2013). Available at: http://www.criticalthinking.org/pages/defining-critical-thinking/766 [Accessed 16 Dec 2015]

[8] Wikipedia, Critical Thinking. Available at: http://en.wikipedia.org/wiki/Critical thinking [Accessed 16 Dec 2015]

[9] Dewey, J. (1909). How We Think. D.C. Heath and Co., Boston, MA.

[10] Glaser, E.M. (1941). An Experiment in the Development of Critical Thinking. Teacher's College, Columbia University.

[11] Oxford Dictionaries (2015). Available at: www.oxforddictionaries.com [Accessed 16 Dec 2015]

[12] Bloom, B.S. (1956). (Ed) Taxonomy of Educational Objectives, the classification of educational goals - Handbook l: Cognitive Domain. McKay, New York.

[13] Davies, M. (2011). Introduction to the special issue on critical thinking in higher education. Higher Education Research and Development, 30(3), pp255-260. Available at:

http://www.tandfonline.com/doi/abs/10.1080/07294360.2011.562145\#.VeA2pvlVhBc [Accessed 16 Dec 2015]

[14] Davidson, M. (2009). The culture of critical thinking. Available at: http://www.nottingham.ac.uk/pesl/internationalisation/curriculum/documents/2/ [Accessed 16 Dec 2015]

[15] Floyd, C.B. (2011). Critical thinking in a second language. Higher Education Research and Development, 30(3), pp289-302 Available at:

http://www.tandfonline.com/doi/pdf/10.1080/07294360.2010.501076 [Accessed on 16 Dec 2015]

[16] Forbes (2012). The 10 Skills That Will Get You a Job in 2013. Available at: http://www.forbes.com/sites/meghancasserly/2012/12/10/the-10-skills-that-will-get-you-a-job-in2013/ [Accessed 16 Dec 2015]

[17] Engineering Council (2014). The Accreditation of Higher Education Programmes: UK Standard for Professional Engineering Competence, Third Edition. Available at: http://www.engc.org.uk/ukspec.aspx [Accessed 16 Dec 2015]

[18] International Engineering Alliance (2013). Graduate Attributes and Professional Competencies, Version 3. Available at: http://www.ieagreements.org/GradProfiles.cfm [Accessed 16 Dec 2015]

[19] Bowman, M. and Sidwell, K. (2009). Teaching Critical Thinking Skills: A Case Study from Mechanical Engineering. Available at:

http://www.Its.leeds.ac.uk/news/conference_09 10/Abstract_Homepage_LTC6_2009.php?PAG $\mathrm{E}=5 \&$ SUBPAGE $=105$ [Accessed 16 Dec 2015]

[20] Wass, R., Harland, T., \& Mercer, A. (2011). Scaffolding critical thinking in the zone of proximal development. Higher Education Research and Development, 30(3), pp255-260. Available at: http://www.tandfonline.com/doi/full/10.1080/07294360.2010.489237\#abstract [Accessed 16 Dec 2015]

[21] Fisher, A. (2001). Critical Thinking: An Introduction. Cambridge University Press.

[22] Felder, R.M. and Brent, R. (2014). Want your students to think creatively and critically? How about teaching them? Chemical Engineering Education, 48 (2), pp113-114.

[23] Gunnink, B. and Sanford Bernhardt, K.L. (2002). Writing, Critical Thinking and Engineering Curricula. $32^{\text {nd }}$ ASEE/IEEE Frontiers in Education Conference, 2002, Boston, MA

[24] Playle, J.F. (2000). Critically appraising research studies. Journal of Community Nursing, 14(11), pp10-16. 
[25] AACU. (2010). Critical thinking VALUE rubric. Available at:

http://www.aacu.org/value/rubrics/critical-thinking. [Accessed 16 Dec 2015]

[26] Alfrey, K. \& Cooney, E. (2009). Developing a Rubric to Assess Critical Thinking in Assignments with an Open-Ended Component. Proceedings of the 2009 American Society for Engineering Annual Conference and Exposition, Austin, Texas, AC2009-653. 